\title{
Mobile outreach health services for mothers and children in conflict-affected and remote areas: a population-based study from Afghanistan
}

\author{
Karen Edmond, ${ }^{1}$ Khaksar Yousufi, ${ }^{2}$ Malalai Naziri, ${ }^{2}$ Ariel Higgins-Steele, ${ }^{2}$ \\ Abdul Qadir Qadir, ${ }^{3}$ Sayed Masoud Sadat, ${ }^{3}$ Alexandra L Bellows, ${ }^{4}$ Emily Smith ${ }^{4}$
}

${ }^{1}$ United Nations Childrens Fund, Kabul, Afghanistan ${ }^{2}$ UNICEF, Kabul, Afghanistan ${ }^{3}$ Ministry of Public Health, Kabul, Afghanistan ${ }^{4}$ Harvard T.H. Chan School of Public Health, Boston, USA

\section{Correspondence to}

Dr Karen Edmond, United Nations Childrens Fund, Kabul, Afghanistan;

karen.edmond@uwa.edu.au

Received 5 January 2019 Revised 11 April 2019 Accepted 16 June 2019 Published Online First

3 July 2019

\section{Linked}

- http://dx.doi.org/10.1136/ archdischild-2019-317746

Check for updates

(C) Author(s) (or their employer(s)) 2020. № commercial re-use. See rights and permissions. Published by BMJ.

To cite: Edmond K, Yousufi K, Naziri M, et al. Arch Dis Child

2020:105:18-25.

\section{ABSTRACT}

Objective To assess whether sustained, scheduled mobile health team (MHT) services increase antenatal care (ANC), postnatal care (PNC) and childhood immunisation in conflict-affected and remote regions of Afghanistan.

Design Cross-sectional, population-based study from 2013 to 2017. Proportions were compared using multivariable linear regression adjusted for clustering and socio-demographic variables.

Setting 54 intervention and 56 control districts in eight Afghanistan provinces.

Participants 338796 pregnant women and 1693872 children aged under 5 years.

Interventions 'Intervention districts' that received MHT services for 3 years compared with 'control districts' in the same province without any MHT services over the same period.

Main outcome measures District-level and cliniclevel ANC, PNC, childhood immunisation (pentavalent 3, measles 1), integrated management of childhood immunisation services.

Results Proportion of pregnant women receiving at least one ANC visit was higher in intervention districts $(83.6 \%, 161750 / 193482)$ than control districts $(61.3 \%$, 89 077/145 314) (adjusted mean difference (AMD) $14.8 \% ; 95 \% \mathrm{Cl}: 1.6 \%$ to $28.0 \%$ ). Proportion of children under 1 year receiving their first dose of measles vaccine was higher in intervention $(73.8 \%, 142738 / 193412)$ than control districts (57.3\%, 83 253/145 293) (AMD $12.8 ; 95 \% \mathrm{Cl}: 2.1 \%$ to $23.5 \%)$. There was no association with PNC (AMD 2.8\%:95\% Cl: $-5.1 \%$ to $10.7 \%$ ). MHTs did not increase clinic-level service provision for ANC (AMD $41.32 ; 95 \% \mathrm{Cl}:-52.46$ to 135.11 ) or any other outcomes.

Conclusions Sustained, scheduled MHT services to conflict-affected and remote regions were associated with improved coverage of important maternal and child health interventions. Outreach is an essential service and not just an 'optional extra' for the most deprived mothers and children.

\section{INTRODUCTION}

Almost 400 million women and children are estimated to live in conflict-affected areas, and millions more live in hard-to-reach regions in low-income and middle-income countries. ${ }^{12}$ Providing primary care in these contexts is essential. ${ }^{3}$

There have been substantial improvements in maternal and child health $(\mathrm{MCH})$ services in

\section{What is already known on this topic?}

- Three systematic reviews of maternal and child health outreach services reported significant increases in antenatal care, postnatal care and childhood immunisation in non-emergency areas.

- Three studies of short duration mobile services from conflict-affected areas (Myanmar, Pakistan and Nigeria) increased immunisation coverage by $7 \%-50 \%$.

- However, no studies have evaluated impacts of the approach used in Afghanistan of sustained, scheduled mobile service delivery.

\section{What this study adds?}

- Sustained scheduled outreach services from mobile health teams are associated with improved primary care services for women and children in Afghanistan.

- Mobile outreach is an essential service and not just an 'optional extra' for the most hard to reach and deprived mothers and children in Afghanistan.

- Governments and funders of health programmes in other countries with remote and conflict-affected populations need to invest in implementation and evaluation of outreach services.

Afghanistan despite worsening levels of conflict. ${ }^{4}$ However, access to care remains challenging; the proportion of pregnant women receiving any antenatal care (ANC) is below $60 \%$ nationally and less than half of infants received all their vaccinations in 2015..$^{5}$ There are also major disparities, with much poorer service provision in conflict-affected and remote areas. $^{5-7}$

Outreach healthcare is needed to reach the most vulnerable women and children in remote areas and conflict-affected countries such as Afghanistan. ${ }^{3}$ Mobile health teams (MHTs) have been part of the Ministry of Public Health (MoPH) standard package of health services in Afghanistan since $2003 .^{7}$ These MHTs visit remote and conflictaffected villages for 1 to 2 days every 2 months. However, this type of 'sustained standard package' 


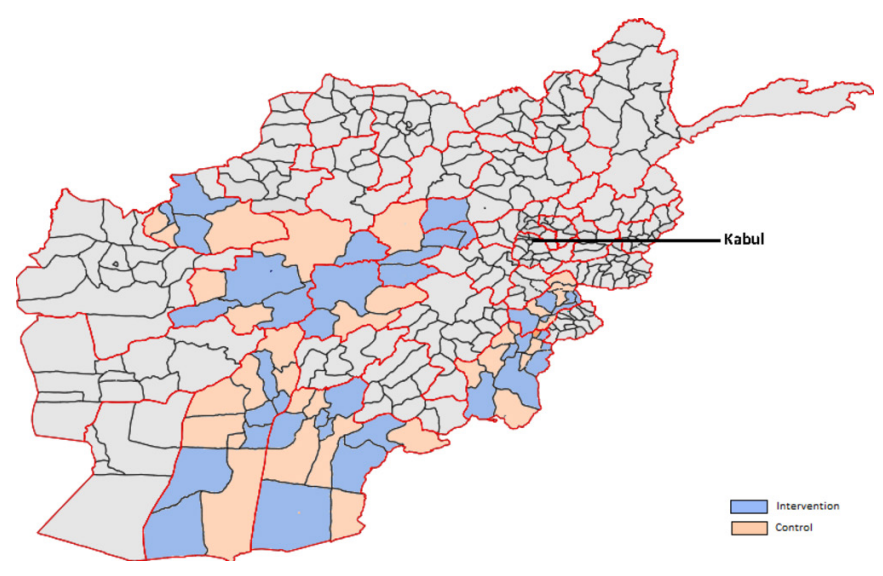

Figure 1 Geographical distribution of the Afghanistan mobile health teams by district from March 2016 to March 2017.

approach has not been evaluated. To our knowledge, there have been only three published outreach evaluations in conflictaffected and remote areas. ${ }^{8-10}$ One study evaluated specialised maternal services in remote Myanmar, ${ }^{9}$ one study evaluated a Polio campaign camp in Pakistan ${ }^{10}$ and one study examined regular visits from a focused MHT programme that was not part of the routine health system in Nigeria. ${ }^{8}$
Thus, our overall aim was to assess the effectiveness of sustained standard service delivery from MHT outreach services in improving primary care for mothers and children in conflictaffected and remote areas. The primary objective was to assess the association between MHTs and service utilisation for essential preventive services such as ANC, postnatal care (PNC) and childhood immunisation. Secondary objectives were to assess associations between MHTs and referral for facility deliveries and integrated management of childhood illnesses (IMCI) treatment. In addition, we assessed effects on service provision at district health centres.

\section{METHODS}

\section{Study design and setting}

This was a cross-sectional, population-based study conducted over a 48-month period from March 2013 to March 2017 in eight provinces of Afghanistan (figure 1).

There are functional hospital and health centres throughout Afghanistan (table 1) though services can be forced to close by anti-government elements. The MoPH defines an 'open' health centre as a clinic that is able to serve clients for at least 6 hours per day for at least 15 of the preceding 30 days $^{7}$ (table 2). $\mathrm{MoPH}$ outreach services include the following: (i) 'Vaccination outreach' from clinics to surrounding villages returning to base the same day; (ii) 'Mobile clinics' providing adult trauma

Table 1 Definitions of terms and covariates used in the study

\begin{tabular}{|c|c|}
\hline \multicolumn{2}{|l|}{ Health services } \\
\hline Sub-health centre & $\begin{array}{l}\text { Targeted to whole population } \\
\text { Staffed by generalist nurse, vaccinator, midwife } \\
\text { Provide ANC, PNC, growth monitoring, vaccination and integrated management of childhood illness clinics but no delivery care or } \\
\text { emergency care (emergency cases are stabilised and referred to } \mathrm{BHC}, \mathrm{CHC} \text { or } \mathrm{DH})^{12}\end{array}$ \\
\hline BHC & $\begin{array}{l}\text { Targeted to whole population } \\
\text { Staffed by generalist nurse, vaccinator, midwife } \\
\text { Provide services as above but also assistance to normal deliveries (emergency cases are stabilised and referred to BHC, CHC or DH) }{ }^{12}\end{array}$ \\
\hline $\mathrm{CHC}$ & $\begin{array}{l}\text { Targeted to whole population } \\
\text { Staffed by generalist nurse, vaccinator, midwife, doctor } \\
\text { Provide services as above but also basic emergency obstetric care from a midwife which includes manual removal of placenta and } \\
\text { retained products, blood transfusion, basic laboratory services. Also provides vaccination outreach (one outreach service per CHC) }\end{array}$ \\
\hline DH & $\begin{array}{l}\text { Targeted to whole population } \\
\text { Staffed by generalist nurse, vaccinator, midwife, doctor } \\
\text { Provide services as above but also comprehensive emergency obstetric care from a doctor or nurse which includes surgery, } \\
\text { anaesthesia and caesarean section. No outreach vaccination service }{ }^{12}\end{array}$ \\
\hline Vaccination outreach services & $\begin{array}{l}\text { Targeted to pregnant women and children } \\
\text { Staffed by male vaccinator on motor bicycle } \\
\text { Provide vaccination services four times per month by staff who travel from the fixed centre to surrounding villages by motorcycle } \\
\text { and return to base the same day; and one vaccination service per } \mathrm{CHC}^{12}\end{array}$ \\
\hline Mobile health teams & $\begin{array}{l}\text { Targeted to pregnant women and children under } 5 \text { years } \\
\text { Staffed by midwife, vaccinator, nurse } \\
\text { Provide ANC, PNC, vaccinations, treatment of childhood illnesses, advise on referral and transport of all deliveries and complicated } \\
\text { cases. If deliveries occurred while the MHTs are in a village, the MHT midwives assist and organise follow-up; and ongoing sustainec } \\
\text { scheduled service delivery to the most remote and conflict-affected villages every } 2 \text { months and return to base every } 4-6 \text { weeks }\end{array}$ \\
\hline Health facility density & Population per health facility \\
\hline \multicolumn{2}{|l|}{ Socio-demographics } \\
\hline Lowest wealth quintile & Women scored in asset index as being in the lowest $20 \%$ of the population ${ }^{5}$ \\
\hline No female education & Women with no formal education ${ }^{5}$ \\
\hline No female careseeking & Women who report having to ask permission before seeking healthcare ${ }^{5}$ \\
\hline \multicolumn{2}{|l|}{ Access } \\
\hline Remote & District centre more than 2 hours by any form of transport from provincial capital ${ }^{16}$ \\
\hline Mountainous & More than $1800-\mathrm{km}$ elevation at highest point of district ${ }^{16}$ \\
\hline High security risk & $\begin{array}{l}\text { Use of armed force between warring parties in a conflict dyad, state-based or non-state, resulting in deaths). } 25 \text { deaths or less in } \\
\text { the previous } 12 \text { months is categorised as low intensity security risk, } 25-100 \text { is categorised as moderate intensity security risk and } \\
100+\text { is categorised as high intensity security risk }\end{array}$ \\
\hline
\end{tabular}

ANC, antenatal care; BHC, basic health centre; CHC, comprehensive health centre; DH, district hospital; PNC, postnatal care. 
Original article

Table 2 Characteristics of intervention and control districts from March 2016 to March 2017

\begin{tabular}{|c|c|c|}
\hline & Intervention districts $(n=54)$ & Control districts $(n=56)$ \\
\hline \multicolumn{3}{|l|}{ Population } \\
\hline Total population & 4837198 & 3767060 \\
\hline Mean (SD) population per district & $89577(53486)$ & $67268(78$ 586) \\
\hline Total number of pregnant women & 193482 & 145314 \\
\hline Mean (SD) number of pregnant women per district & $3583(3129)$ & $2691(3143)$ \\
\hline Total number of children under 5 years & 967410 & 726462 \\
\hline Mean (SD) number of children under 5 years per district & $17915(10697)$ & $13453(15717)$ \\
\hline \multicolumn{3}{|l|}{ Socio-demographics* } \\
\hline Mean (SD) \% lowest wealth quintile & $34.95(32.63)$ & $15.24(25.56)$ \\
\hline Mean (SD) \% no female education & $76.3(12.78)$ & $84.12(10.33)$ \\
\hline Mean (SD) \% female careseeking & $63.3(18.40)$ & $56.20(18.41)$ \\
\hline \multicolumn{3}{|l|}{ Access* } \\
\hline$\%$ Remote & $90.7 \%$ & $94.6 \%$ \\
\hline$\%$ Mountainous & $75.9 \%$ & $53.9 \%$ \\
\hline$\%$ High security risk & $68.5 \%$ & $89.3 \%$ \\
\hline \multicolumn{3}{|l|}{ Fixed health services* } \\
\hline Total number of fixed health facilities (SHC, BHC, CHC, DH) & 260 & 149 \\
\hline Number of SHCs & 84 & 29 \\
\hline Mean (SD) SHCs per district & $1.56(1.78)$ & $0.52(0.74)$ \\
\hline Mean (SD) population per SHC & $57586(51249)$ & $129899(38303)$ \\
\hline Number of BHCs & 115 & 73 \\
\hline Mean (SD) BHCs per district & $2.13(1.73)$ & $1.30(1.14)$ \\
\hline Mean (SD) population per BHC & $42063(26971)$ & $51604(83045)$ \\
\hline Number of $\mathrm{CHCs}$ & 47 & 43 \\
\hline Mean (SD) CHCs per district & $0.87(0.80)$ & $0.77(1.28)$ \\
\hline Mean (SD) population per CHC & $102919(45012)$ & $87606(35552)$ \\
\hline Number of district hospitals & 14 & 4 \\
\hline Mean (SD) DHs per district & $0.26(0.44)$ & $0.07(0.26)$ \\
\hline Mean (SD) population per DH & $87606(38858)$ & $941765(33189)$ \\
\hline Health facility density (population per health facility) & 18605 & 25282 \\
\hline Health facility density (pregnant women and children under 5 years population per health facility) & 4466 & 5852 \\
\hline \multicolumn{3}{|l|}{ Outreach health services } \\
\hline Total number of outreach health services & 106 & 43 \\
\hline Number of vaccination outreach services & 47 & 43 \\
\hline Mean (SD) vaccination outreach per district & $0.87(0.80)$ & $0.77(1.28)$ \\
\hline Mean (SD) population per vaccination outreach & $4115(2001)$ & $3378(1976)$ \\
\hline Number of MCH mobile health teams & 59 & 0 \\
\hline Mean (SD) MCH mobile health teams per district & $1.09(0.35)$ & - \\
\hline Mean (SD) population per MCH mobile health team & $84018(46112)$ & - \\
\hline Number of other mobile health services & 10 & 11 \\
\hline Mean (SD) other mobile health services per district & $0.241(0.581)$ & $0.143(0.401)$ \\
\hline Mean (SD) population per other mobile health service & $483720(198888)$ & $342460(145720)$ \\
\hline
\end{tabular}

*See table 1 for definitions.

BHC, basic health centre; $\mathrm{CHC}$, comprehensive health centre; $\mathrm{DH}$, district hospital; $\mathrm{SHC}$, sub-health centre.

and non-communicable disease care and (iii) scheduled service delivery from 'MCH -MHTs' targeted to pregnant women and children under 5 years. The MHTs visit remote villages every 2 months and return to base every $4-8$ weeks. A village can only receive the services of a $\mathrm{MCH}-\mathrm{MHT}$ if the travel time to the nearest open health centre by any available transport system is more than 2 hours. Outreach services are purposively allocated to districts by provincial health directorates after submissions are received from district health directorates. ${ }^{71112}$

Implementation of all MHTs in all 54 districts commenced by March 2013. In this study, districts that had received $\mathrm{MCH}-$ MHT services for at least the previous 3 years were classified as 'intervention districts' and districts in the same province without any $\mathrm{MCH}-\mathrm{MHT}$ services in the previous 3 years were 'control districts' (figure 1).

\section{Intervention}

There were 8 provinces and 54 districts with MCH-MHTs functioning from 2013 to 2017 (figure 1). The intervention districts had one $(n=50,93 \%)$, two $(n=3,6 \%)$ or three $(n=1$, $1 \%)$ MHTs. Each team serviced an average of 40 villages (range: 31-49). The duration of the MHT visits ranged from 1 to 2 days depending on the size of the village.

The MHTs consisted of an Afghan MoPH accredited midwife, vaccinator and generalist nurse. The MHT provided primary 
care services to pregnant and postpartum women, and children aged under 5 years including ANC, PNC, newborn care, nutrition and breastfeeding counselling, maternal and childhood vaccinations and IMCI. The MHTs also advised on referral of deliveries and complicated cases. If deliveries occurred while the team was in a village, the MHT midwives assisted and organised follow-up.

Each MHT registered their ANC, PNC, newborn care, maternal and childhood vaccinations, IMCI episodes of care ('occasions of service') in registers at the point of care according to MoPH Health Management Information System (HMIS) standard operating procedures (SOPs).

The MHTs received supportive supervision from a senior nurse who travelled each month from the provincial capital to each team. MoPH MHT coordinators monitored activities and data via monthly scheduled and unscheduled visits. MHTs also received yearly refresher training.

\section{Controls}

In all, 56 districts in the eight provinces had no services from a MHT within the previous 3 years and were designated as 'control' districts (table 2). These control districts received standard care from $\mathrm{MoPH}$ health centres including outreach vaccination services and adult mobile health services.

All health centres and district hospitals in the intervention and control areas have received a health system strengthening package from Unicef and the MoPH from 2012 to the current time. This has included standard MoPH ANC, PNC, IMCI and immunisation training packages. ${ }^{7}$

\section{Data collection}

Service provision data were obtained from the National HMIS for the period from 22 March 2016 to 21 March $2017 .{ }^{13}$ In Afghanistan, all health service providers in all health facilities (hospital, clinic, vaccination outreach, MHTs) are trained to collect de-identified HMIS data on their episodes of care ('occasions of service') using standardised paper forms which are entered into Access databases in the provincial capitals. An independent third-party monitoring system verifies and validates HMIS data. 71415

District-level data on socio-demographics (wealth quintile, female education, female careseeking), access (security risk, mountainous, remoteness) and health system characteristics (clinic type, clinic catchment population, clinic density) were obtained from the Afghanistan Demographic and Health Survey 2015, HMIS client and HMIS facility survey reports. 5131617

Population denominators were obtained from the Central Statistics Organisation (CSO) standard MoPH 2016 health facility catchment area annual census using defined $\mathrm{MoPH}$ SOPs. ${ }^{13} 16$

\section{Statistical methods}

The primary outcome measure was the proportion of pregnant women who were recorded in HMIS as having received at least one ANC visit.

For district-level data, the proportion of women receiving services in intervention districts was compared with control districts using linear regression. Minimally adjusted models included only a random intercept for district. Fully adjusted models controlled for access (security risk, mountainous, remoteness), socio-demographic characteristics (wealth quintile, female education, female careseeking), clinic density (number of clinics per catchment population) and a random intercept for each district.

For clinic-level data, service provision in clinics in the intervention districts was compared with service provision in clinics in the control districts also using linear regression. Minimally adjusted models included only a random intercept for district. Fully adjusted models controlled for access, facility type, size of clinic catchment population and a random intercept for each district.

Random effects were used to adjust for clustering. ${ }^{18}$ For each outcome, mean differences (MDs), adjusted mean differences (AMDs), 95\% CIs and corresponding $\mathrm{p}$ values were calculated. Similar methods were used for the secondary outcomes (PNC, childhood immunisations (pentavalent 3, measles 1), facility delivery, IMCI services).

The figures were produced using library ggplot 2 in ' $R$ '. The linear model and 'line' was computed using 'geom_smooth' command in ggplot $2 \mathrm{R}$ which fits an unadjusted linear regression. All other analyses were conducted using SAS V.9.4.

We calculated that we required a sample size of 178077 women in the 110 districts to provide $90 \%$ power at a 5\% significance level for the primary outcome. ${ }^{19}$ These calculations were based on data at the district level, ${ }^{13}$ which estimated a baseline level of at least one ANC visit of $61 \%$, range of ANC across the 110 districts of $20 \%-80 \%$; intervention effect size of $10 \%$; average number of individuals per district of 3180; design effect of $29.6 \%$ and a coefficient of variation $(\mathrm{k})$ of $0.24 .{ }^{19}$ We calculated that this sample size would provide adequate power for the secondary outcomes as well.

Approvals for this study and for using de-identified HMIS data were provided by the MoPH General Directorate of Policy and Planning.

\section{RESULTS}

\section{Baseline characteristics}

There were 338796 pregnant women and 1693872 children aged under 5 years in the 54 intervention and 56 control districts in the study area (table 2).

The intervention districts were similar to control districts. However, the intervention districts had more women in the lowest wealth quintile (35.0\% intervention, 15.2\% control) and poorer female careseeking (63.3\% intervention, $56.2 \%$ control) than the control districts. The intervention districts were also more mountainous (75.9\% intervention, $53.9 \%$ control) but had a lower security risk (68.5\% intervention, $89.3 \%$ control) than the control districts (table 2).

There were more fixed centres per $\mathrm{MCH}$ population in the intervention $(260,1 / 4466)$ than the control $(149,1 / 5852)$ districts. However, there were fewer vaccination outreach services per $\mathrm{MCH}$ population in the intervention compared with the control districts (47, 1/4115 intervention, 43, 1/3378 control) and fewer mobile clinics per total population (10, 1/483 720 intervention, 11, 1/342 460 control) (table 2).

\section{District-level services}

The proportion of pregnant women who received at least one ANC visit was higher in the intervention (83.6\%) compared with the control (61.3\%) districts (AMD 14.8\%; 95\% CI: $1.6 \%$ to $28.0 \%$ ) (table 3 ). The proportion of children who received measles vaccine was higher in the intervention $(73.8 \%)$ compared with the control (57.3\%) districts (AMD 12.8; 95\% CI: $2.1 \%$ to $23.5 \%$ ). The proportion of children who received at least one IMCI visit was higher in the intervention $(33.6 \%)$ 
compared with the control (22.6\%) districts (AMD 10.3; 95\% CI: $1.4 \%$ to $19.3 \%)$. Coverage was also higher in intervention compared with control districts for the other secondary outcomes (PNC, health facility delivery, tetanus toxoid vaccine, pentavalent vaccine), though these effects did not reach statistical significance (table 3).

Coverage levels for maternal and childhood services were similar in small and large districts (figures 2 and 3). There was also a consistent linear 'tandem' relationship between the intervention and control districts by utilisation for ANC and facility delivery (figure 2), and measles vaccine and IMCI services (figure 3). The figures also show that the districts with the intervention had, on average, higher utilisation of healthcare services compared with non-intervention districts.

\section{Clinic-level services}

There was no statistical evidence of an effect of the MHT intervention on clinic-level service provision in the intervention and control areas (table 4). For pregnant women, the mean number of ANC services provided by each facility were similar for clinics in the intervention (mean 468; SD 481) and control (mean 437; SD 348) districts (AMD 41.32; 95\% CI: -52.46 to 135.11). PNC visits (AMD 10.68; 95\% CI: -33.12 to 54.49 ) and health facility deliveries (AMD 119.35; 95\% CI: -9.48 to 248.19 ) were also similar. Pentavalent vaccine visits were similar in clinics in the intervention (mean 514, SD 493) and control (mean 530, SD 393 ) districts (AMD 74.14; 95\% CI: -13.52 to 161.8 ). Measles vaccine (AMD 83.79; 95\% CI: -1.44 to $169.03, \mathrm{p}=0.051$ ) and IMCI visits were also similar (AMD 280.95; 95\% CI: -40.11 to $602.00, \mathrm{p}=0.09$ ).

\section{DISCUSSION}

Despite increasing levels of conflict across our study area in Afghanistan, we found a consistent association between implementation of MHTs and improved coverage of important $\mathrm{MCH}$ interventions across 110 conflict-affected and remote districts. ANC coverage was almost $15 \%$ higher in intervention (83.6\%) compared with control (61.3\%) districts. Similar associations were seen for measles vaccine and IMCI coverage. Facility delivery, PNC and pentavalent vaccine coverage were higher in intervention than control districts, though these results did not reach statistical significance. There was no change in clinic use.

Unicef and the WHO recently reported that provision of outreach services to children who live in deprived areas is highly cost-effective. ${ }^{20}{ }^{21}$ The Unicef-WHO model estimates that for each \$1 million invested in outreach services, approximately 97 children's lives can be saved in the most deprived populations versus 61 lives in the least deprived populations. ${ }^{20}{ }^{21}$ However, outreach and MHTs in remote and conflict-affected areas are considered 'expensive' by many governments who request local data on effectiveness and cost including transport to remote villages and per diem payments. ${ }^{22} 23$

Three systematic reviews have reported important effects of $\mathrm{MCH}$ outreach delivery strategies on $\mathrm{MCH}$ service provision in non-emergency areas. ${ }^{24-26}$ Three additional studies have reported important impacts on $\mathrm{MCH}$ service delivery in conflict settings. ${ }^{8-10}$ In Myanmar, specialised maternal services in border camps increased ANC and PNC by 32\%-50\%. ${ }^{9}$ Polio campaign camps in conflict-affected areas of Pakistan increased vaccination rates by $7 \%-9 \% .{ }^{10}$ Regular visits from a MHT programme funded by the Polio programme in Nigeria increased coverage of children 'fully immunised' by $33 \%-36 \% .{ }^{8}$ 


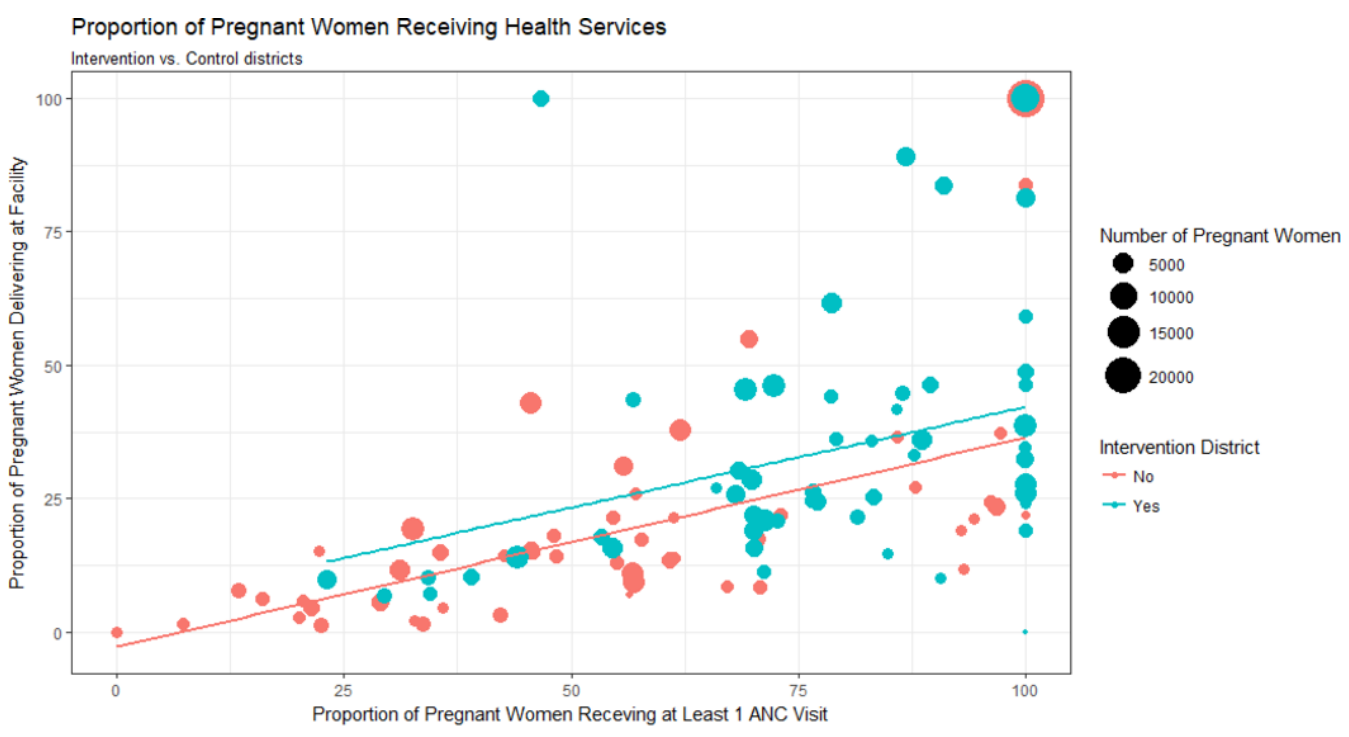

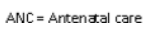

Figure 2 Proportion of women receiving maternal health services in intervention and control districts from March 2016 to March 2017. ANC, antenatal care.

However, no studies appear to have examined impacts of sustained, scheduled MHT services, embedded within the traditional health system, to conflict-affected areas, as examined in our study. Ongoing follow-up is an essential part of primary healthcare. Sustained contact from the same service provider helps families develop trust and increases demand. ${ }^{272}$ Repeated visits also enable MHTs to engage with village leaders and local 'access negotiators' in conflict-affected areas.

We are also aware that the control districts without MHTs in our study area were also in need of $\mathrm{MCH}$ mobile services. Unicef is actively working with the directorates in these control districts to implement more MHTs. Indeed, in the 6 months since the data analysis was completed, ten more MHTs have been implemented in the control districts and the plan is to completely cover the control districts over the next 3 years.
Our study had some limitations. We were unable to collect cost data. Our study was non-randomised and intervention districts were purposively chosen by provincial health staff. There were differences in baseline characteristics between the intervention and control groups. However, we adjusted for all important covariates. Our population denominators were obtained from CSO data last updated in 2012, ${ }^{16}$ and there have been significant population movements since that time. ${ }^{6}$ However this problem is likely to be non-differential. Our outcome data were routinely reported HMIS data which are well known to have data quality issues in low income countries. ${ }^{315}$ However, unlike many other HMIS systems, there is a robust well-funded independent monitoring mechanism which has been well validated in Afghanistan. ${ }^{15}$ Further, any bias in over-reporting is likely to be non-differential. Finally, due to a lack of a clear baseline (ie, the

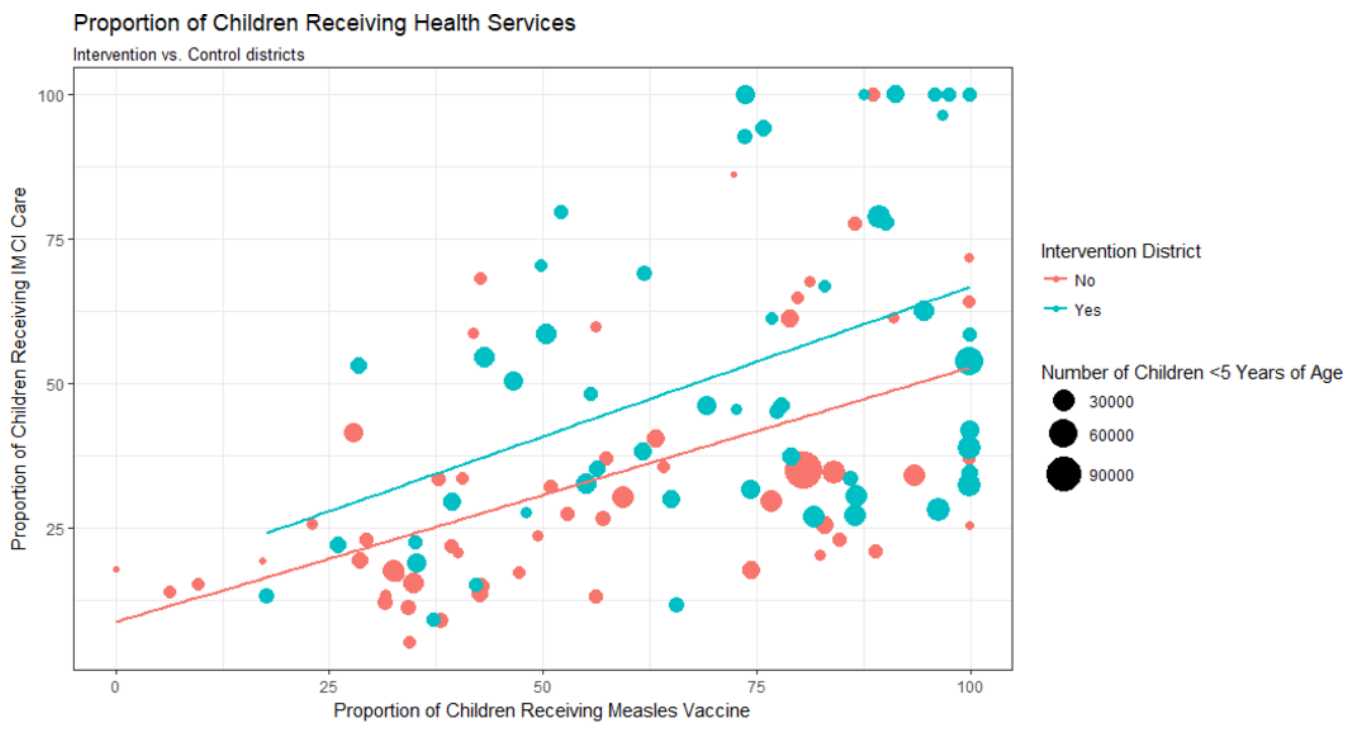

IMCI = Integrated management of child hood illnesses

Figure 3 Proportion of children receiving child health services in intervention and control districts from March 2016 to March 2017. 
Table 4 Clinic service provision compared between intervention and control districts from March 2016 to March 2017

$\begin{array}{llll}\text { Intervention } & \text { Control } & \text { Minimally adjusted mean } & \text { Fully adjusted mean } \\ \text { districts mean } & \text { districts mean } & \text { difference* } & \text { differencet } \\ & \text { (SD) } & \text { (SD) } & \text { (95\% }\end{array}$

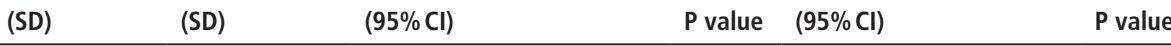

\begin{tabular}{|c|c|c|c|c|c|c|}
\hline \multicolumn{7}{|l|}{ Maternal services } \\
\hline Number of pregnant or postpartum women & $n=193482$ & $n=145314$ & & & & \\
\hline Mean population of pregnant women per clinic & 786 & 1002 & - & - & - & - \\
\hline Mean (SD) number of ANC visits per clinic & $468(481)$ & $437(348)$ & $44.1(-71.16$ to 159.36$)$ & 0.45 & $41.32(-52.46$ to 135.11$)$ & 0.37 \\
\hline $\begin{array}{l}\text { Mean (SD) number of tetanus toxoid vaccines for } \\
\text { pregnant women per clinic }\end{array}$ & $523(599)$ & $496(444)$ & $35.36(-99.29$ to 170.01$)$ & 0.60 & 82.01 ( -38.69 to 202.71$)$ & 0.18 \\
\hline Mean (SD) number of facility deliveries per clinic & $198(631)$ & $136(241)$ & 62.64 (-49.7 to 174.98$)$ & 0.27 & 119.35 (-9.48 to 248.19$)$ & 0.07 \\
\hline Mean (SD) number of PNC visits per clinic & $175(223)$ & $141(169)$ & $32.39(-11.89$ to 76.66$)$ & 0.15 & $10.68(-33.12$ to 54.49$) \ddagger$ & 0.63 \\
\hline \multicolumn{7}{|l|}{ Child health services } \\
\hline Number of children under 1 year & $n=193412$ & $n=145293$ & & & & \\
\hline Mean population of children under 1 year per clinic & 786 & 1002 & - & - & - & - \\
\hline $\begin{array}{l}\text { Mean (SD) number of third pentavalent vaccines for } \\
\text { children under } 1 \text { year per clinic }\end{array}$ & $514(493)$ & $530(393)$ & $-5.73(-111.50$ to 122.96$)$ & 0.92 & $-74.14(-13.52$ to 161.8$)$ & 0.10 \\
\hline $\begin{array}{l}\text { Mean (SD) number of measles vaccines for children } \\
\text { under } 1 \text { year per clinic }\end{array}$ & $484(484)$ & $498(383)$ & $-11.46(-105.45$ to 128.38$)$ & 0.85 & $-83.79(-1.44$ to 169.03$)$ & 0.05 \\
\hline Number of children under 5 years & $n=967410$ & $n=726462$ & & & & \\
\hline Mean population of children under 5 years per clinic & 3933 & 5010 & - & - & - & - \\
\hline $\begin{array}{l}\text { Mean (SD) number of IMCI visits for diarrhoea or } \\
\text { pneumonia for children under five per clinic }\end{array}$ & $1403(1753)$ & $1212(1011)$ & $226.16(-123.81$ to 576.13$)$ & 0.20 & $280.95(-40.11$ to 602.00$)$ & 0.09 \\
\hline
\end{tabular}

${ }^{*}$ Adjusted for random effects by district.

†Adjusted for access (security risk, mountainous, remoteness), facility type, size of clinic population and random effects by district.

¥Estimated $\mathrm{G}$ matrix is not positive definite. Models ran without random effects by district.

ANC, antenatal care; IMCl, integrated management of childhood illnesses; PNC, postnatal care.

initial implementation of the MHTs was staggered) we could not conduct an interrupted time series or 'difference in difference' analysis to evaluate outcomes.

Important strengths of our study included our populationbased implementation. We also included a large sample size of pregnant mothers and children under 5 years. To our knowledge this is the first MHT evaluation conducted at this scale in such a difficult and conflict-affected environment.

Overall, our MHT intervention appeared to improve preventive (ANC, childhood vaccination) and IMCI curative care for pregnant women and children. However, MHTs did not clearly improve health facility referral for delivery and there was no change in clinic use. We feel the higher coverage in the intervention areas is most likely attributable to the MHT efforts rather than referrals to clinics. However, more investigation of this issue is needed. Referral problems in countries like Afghanistan are felt to be due to lack of access to transport, lack of funds, and limited decision making power of women. ${ }^{429}$ In Afghanistan, the MoPH and Unicef are developing cash transfer and miniambulance models to assist with referral but implementation remains challenging.

Our study shows that sustained scheduled outreach services from MHTs are associated with improved primary care services for women and children in fragile countries. However, progressive financing systems are required as well as recognition that mobile outreach is an essential service and not just an 'optional extra' for the most hard to reach and deprived mothers and children. Robust cost-effectiveness data are also needed.

Acknowledgements We wish to acknowledge the dedicated work of the staff of the mobile health teams in this study.

Contributors KME conceptualised and wrote the first draft of the paper. The other authors all made substantial contributions to the conception or design of the work or the acquisition, analysis or interpretation of data; and revised the work critically for important intellectual content.
Funding The authors have not declared a specific grant for this research from any funding agency in the public, commercial or not-for-profit sectors.

Competing interests None declared.

Patient consent for publication Not required.

Provenance and peer review Not commissioned; internally peer reviewed.

Data sharing statement There are no available unpublished data from the study.

\section{REFERENCES}

1 Bahgat K, Dupuy K, Østby G. Children and armed conflict. What existing data can tell us. 2017 https://www.prio.org/utility/DownloadFile.ashx?id=1550\&type= publicationfile (Accessed 30 Apr 2018).

2 Save the children. War on children 2017. https://www.savethechildren.net/ waronchildren/pdf/waronchildren.pdf (Accessed 2 Jan 2018).

3 Blanchet K, Ramesh A, Frison S, et al. Evidence on public health interventions in humanitarian crises. Lancet 2017;390:2287-96.

4 Akseer N, Salehi AS, Hossain SM, et al. Achieving maternal and child health gains in Afghanistan: a Countdown to 2015 country case study. Lancet Glob Health 2016;4:e395-413.

5 Central Statistics Organisation (CSO). Ministry Public Health (MoPH) and ICF 2017. Demographic and Health Survey 2015. Kabul Afghanistan: Central Statistics Organization.

6 Higgins-Steele A, Lai D, Chikvaidze P, et al. Humanitarian and primary healthcare needs of refugee women and children in Afghanistan. BMC Med 2017;15:196.

7 Afghanistan Basic Package of Health Services (BPHS). Ministry of public health. Afghanistan. 2012 http://documents.worldbank.org/curated/en/ 332281468190763772/Afghanistan-Support-to-Basic-Package-of-Health-ServicesBPHS-Project (Accessed 23 Mar 2018).

8 Ongwae KM, Bawa SB, Shuaib F, et al. Use of dedicated mobile teams and polio volunteer community mobilizers to increase access to zero-dose oral poliovirus vaccine and routine childhood immunizations in settlements at high risk for polio transmission in Northern Nigeria. J Infect Dis 2017;216(Suppl 1):S267-72.

9 Mullany LC, Lee TJ, Yone L, et al. Impact of community-based maternal health workers on coverage of essential maternal health interventions among internally displaced communities in eastern Burma: the MOM project. PLoS Med 2010;7:e1000317.

10 Habib MA, Soofi S, Cousens S, et al. Community engagement and integrated health and polio immunisation campaigns in conflict-affected areas of Pakistan: a cluster randomised controlled trial. Lancet Glob Health 2017;5:e593-e603. 
11 KIT Royal Tropical Institute 2016. The balanced scorecard report. basic package of health services 2016. KIT Royal Tropical Institute. 2016 https://www.kit.nl/wpcontent/uploads/2018/10/BPHS-BSC-report-2016-final.pdf (Accessed 1 Apr 2018).

12 Ministry of Public Health, Islamic Republic of Afghanistan. Reproductive Maternal Child Health (RMNCH)-Mobile Package of Services, 2014.

13 HMIS. Afghanistan health management information system. 2017 http://moph.gov.af/ en/documents/category/health-management-information-system (Accessed $23 \mathrm{Mar}$ 2018).

14 Frost A, Wilkinson M, Boyle $P$, et al. An assessment of the barriers to accessing the Basic Package of Health Services (BPHS) in Afghanistan: was the BPHS a success? Global Health 2016;12:71.

15 Edward A, Kumar B, Kakar F, et al. Configuring balanced scorecards for measuring health system performance: evidence from 5 years' evaluation in Afghanistan. PLoS Med 2011;8:e1001066

16 CSO. Afghanistan Central Statistics Organisation. 2016 http://cso.gov.af/en (Accessed 23 Mar 2018).

17 The World Bank Data 2018. Fragile and conflict affected situations. https://data. worldbank.org/region/fragile-and-conflict-affected-situations (Accessed 24th Apr 2018).

18 Kirkwoood B, Sterne J. Essential medical statistics. Oxford, UK: Blackwell Publishing Company, 2003.

19 Hayes RJ, Bennett S. Simple sample size calculation for cluster-randomized trials. Int J Epidemiol 1999;28:319-26.

20 Carrera C, Azrack A, Begkoyian G, et al. The comparative cost-effectiveness of an equity-focused approach to child survival, health, and nutrition: a modelling approach. Lancet 2012:380:1341-51.
21 Chopra M, Sharkey A, Dalmiya N, et al. Strategies to improve health coverage and narrow the equity gap in child survival, health, and nutrition. Lancet 2012;380:1331-40

22 Crocker-Buque T, Edelstein M, Mounier-Jack S. Interventions to reduce inequalities in vaccine uptake in children and adolescents aged $<19$ years: a systematic review. J Epidemiol Community Health 2017;71:87-97.

23 Gopalan SS, Das A, Howard N. Maternal and neonatal service usage and determinant in fragile and conflict-affected situations: a systematic review of Asia and the MiddleEast. BMC Womens Health 2017;17:20.

24 Byrne A, Hodge A, Jimenez-Soto E, et al. What works? Strategies to increase reproductive, maternal and child health in difficult to access mountainous locations: a systematic literature review. PLoS One 2014;9:e87683.

25 Perry HB, Sacks E, Schleiff M, et al. Comprehensive review of the evidence regarding the effectiveness of community-based primary health care in improving maternal, neonatal and child health: 6 . strategies used by effective projects. J Glob Health 2017;7:010906.

26 Lassi ZS, Bhutta ZA. Community-based intervention packages for reducing maternal and neonatal morbidity and mortality and improving neonatal outcomes. Cochrane Database Syst Rev 2015;3:CD007754

27 Mbuagbaw L, Medley N, Darzi AJ, et al. Health system and community level interventions for improving antenatal care coverage and health outcomes. Cochrane Database Syst Rev 2015;12:CD010994.

28 Yonemoto N, Dowswell T, Nagai S, et al. Schedules for home visits in the early postpartum period. Cochrane Database Syst Rev 2017:8:CD009326.

29 Akseer N, Bhatti Z, Rizvi A, et al. Coverage and inequalities in maternal and child health interventions in Afghanistan. BMC Public Health 2016;16(Suppl 2):797. 